\title{
Elevated carboxy terminal cross linked telopeptide of type I collagen in alcoholic cirrhosis: relation to liver and kidney function and bone metabolism
}

\author{
S Møller, M Hansen, J Hillingsø, J-E B Jensen, J H Henriksen
}

\begin{abstract}
Background-The carboxy terminal cross linked telopeptide of type I collagen (ICTP) has been put forward as a marker of bone resorption. Patients with alcoholic liver disease may have osteodystrophy.

Aims-To assess circulating and regional concentrations of ICTP in relation to liver dysfunction, bone metabolism, and fibrosis.

Methods-In 15 patients with alcoholic cirrhosis and 20 controls, hepatic venous, renal venous, and femoral arterial concentrations of ICTP, and bone mass and metabolism were measured.

Results-Circulating ICTP was higher in patients with cirrhosis than in controls. No overall significant hepatic disposal or production was found in the patient or control groups but slightly increased production was found in a subset of patients with advanced disease. Significant renal extraction was observed in the controls, whereas only a borderline significant extraction was observed in the patients. Measurements of bone mass and metabolism indicated only a mild degree of osteodystrophy in the patients with cirrhosis. ICTP correlated significantly in the cirrhotic patients with hepatic and renal dysfunction and fibrosis, but not with measurements of bone mass or metabolism.

Conclusions-ICTP is highly elevated in patients with cirrhosis, with no detectable hepatic net production or disposal. No relation between ICTP and markers of bone metabolism was identified, but there was a relation to indicators of liver dysfunction and fibrosis. As the cirrhotic patients conceivably only had mild osteopenia, the elevated ICTP in cirrhosis may therefore primarily reflect liver failure and hepatic fibrosis. (Gut 1999;44:417-423)
\end{abstract}

Keywords: bone mineral density; carboxy terminal cross linked telopeptide of type I collagen; chronic liver disease; fibrosis; hepatic osteodystrophy; portal hypertension

The formation and resorption of bone are dynamic processes and the amount and composition of bone depend on a balance between the two. ${ }^{1}$ The rate of the individual processes may be estimated by measuring bone matrix components released into the circula- tion during formation or resorption. ${ }^{2}$ Type I collagen is the most abundant protein in the human body. ${ }^{3}$ Most is present in bone and constitutes more than $90 \%$ of the organic matrix; the remainder is found in soft connective tissues all over the body, primarily in the skin. ${ }^{1}$ Several studies have shown that the carboxy terminal propeptide of type I procollagen (PICP) may be a specific marker of bone formation but not of bone resorption. ${ }^{4-7}$ The carboxy terminal cross linked telopeptide of type I collagen (ICTP) seems to represent a new marker of type I collagen degradation. ${ }^{7}{ }^{8}$ It is released into the circulation during degradation of mature type I collagen primarily in bone, and hence it appears to be a potential marker of bone resorption. ${ }^{9}$

Metabolic bone diseases have been recognised for a long time in patients with chronic liver diseases, especially when the aetiology is cholestatic or alcoholic. ${ }^{10-15}$ However, the degree of hepatic osteodystrophy and the clinical severity are still under debate. ${ }^{16-18}$ Recent results have shown increased serum concentrations of ICTP in cirrhosis, ${ }^{19}$ but kinetic studies on ICTP have not been performed in man. The aims of the present study were therefore to assess the circulating and regional concentrations of ICTP in patients with alcoholic cirrhosis and subjects with normal liver function, and to relate ICTP to liver dysfunction and bone metabolism.

\section{Materials and methods}

STUDY POPULATION

The study population consisted of 15 consecutive patients (nine men, six women) with histologically verified cirrhosis. The median age of the patients was 59 years (range 38-69). None of the patients had clinical signs of osteoporosis (fractures of the spine, femoral neck, or radius). All patients had a history of alcohol abuse - that is, a consumption exceeding $50 \mathrm{~g}$ per day for more than five years. The current intake of alcohol was also estimated by measurements of carbohydrate deficient

Abbreviations used in this paper: $\mathrm{BMD}$, bone mineral density; CDT, carbohydrate deficient transferrin; DEXA, dual energy $x$ ray absorptiometry; FN, femoral neck; HBF, hepatic blood flow; ICTP, carboxy terminal cross linked telopeptide of type I collagen; ICG, indocyanine green; MCB, metacarpal bone; PICP, carboxy terminal propeptide of type I procollagen; PIIINP, aminoterminal propeptide of type III procollagen; PTH, parathyroid hormone; RIA, radioimmunoassay; 25-OHD, 25-hydroxyvitamin $\mathrm{D}$; $1,25-\mathrm{OH}_{2} \mathrm{D}, 1,25$-dihydroxyvitamin $\mathrm{D}$. 
transferrin (CDT).$^{20}{ }^{21}$ All had abstained from alcohol for at least one week before the study and none had withdrawal symptoms. According to the modified Child-Turcotte classification, ${ }^{22}$ three patients belonged to class A, six to class B, and six to class $\mathrm{C}$. Eleven of the patients had mild or moderate ascites confirmed by ultrasonography or paracentesis; they were treated with diuretics and put on a sodium restricted diet of $40 \mathrm{mmol}$ per day. Six patients received a diuretic dose of $100 \mathrm{mg}$ spironolactone and five patients received additionally a dose of $40 \mathrm{mg}$ furosemide. Additional cardiovascular medication was not prescribed for any of the patients. All patients received multivitamin B complex. None of the patients had hepatic encephalopathy above grade I or had experienced recent gastrointestinal bleeding.

A matched control group consisted of 10 men and 10 women (median age 55 years, range 30-78) with arterial hypertension or abdominal pain in whom a catheterisation was performed in order to exclude renovascular hypertension or intestinal ischaemia, respectively. None of the controls showed signs of liver disease. Most control patients received cardiovascular medication and were treated with calcium channel blockers $(n=13)$, thiazides $(n=5)$, methyldopa $(n=4)$, beta adrenoceptor blockers $(n=3)$, nitrates $(n=3)$, and angiotensin converting enzyme inhibitors $(n=2)$. Five patients received morphine derivates and two patients allopurinol. One patient received ibuprofen, prednisolone, and azathioprine. Table 1 summarises the clinical and biochemical characteristics of the patients and controls.

Patients and controls participated after giving their informed consent according to the Helsinki II declaration, and the study was approved by the local Ethics Committee for Medical Research in Copenhagen (KF-01128/93). No complications or side effects were encountered during the study.

CATHETERISATION

All patients underwent a haemodynamic investigation to assess the degree of portal venous hypertension. The patients and controls were studied in the morning after an overnight fast and at least one hour resting in the supine position. Catheterisation of hepatic and renal veins was performed as described by Henriksen et $a l .{ }^{23}$ Under local anaesthesia, a Cournand or Swan-Ganz catheter size 7-F was guided to the localisations via the femoral route during fluoroscopic control. Pressures were measured in the wedged and free hepatic vein position in at least three veins, the midaxillary line being zero pressure level. Pressures were measured directly by a capacitance transducer (Simonsen \& Weel, Copenhagen, Denmark) and the mean values of repetitive measurements were used. Hepatic blood flow (HBF) was determined by the indocyanine green (ICG) constant infusion technique. ${ }^{24}$ ICG clearance was measured as the infusion rate divided by the arterial plasma concentration of ICG. Extraction ratios of plasma ICTP from the liver and the kidneys were determined as: (arterial concentration - venous concentration)/arterial concentration. Blood samples from one subject with normal liver function and two patients with cirrhosis were missing for the calculation of renal extraction.

BIOCHEMICAL AND HORMONAL MEASUREMENTS

Blood samples $(10 \mathrm{ml})$ were collected simultaneously from the hepatic vein, the renal vein, and the femoral artery discharging the content of the catheter dead space. The samples were centrifuged immediately at $4^{\circ} \mathrm{C}$ and the serum was stored at $-25^{\circ} \mathrm{C}$ until assayed. Serum concentrations of albumin, bilirubin, aspartate aminotransferase, alkaline phosphatases, coagulation factors 2, 7, and 10, creatinine, calcium, sodium, and potassium were determined by routine methods in an autoanalyser (SMAC, Technicon Instruments Corporation, Tarrytown, New York, USA).

ICTP was analysed by a radioimmunoassay (RIA) with polyclonal rabbit antibodies specific for human ICTP as described elsewhere. ${ }^{9}$ Intra-assay and interassay variations were less than $6 \%$ and $7 \%$, respectively. The detection limit was $0.2 \mu \mathrm{g} / \mathrm{l}$ and the reference interval was $0.8-6.2 \mu \mathrm{g} / 1$. The reference intervals of ICTP, PICP, and PIIINP (aminoterminal propeptide of type III procollegen) are based on measurements from a normal reference population comprising 267 healthy individuals (144 women and 123 men) aged 18-80 years, primarily selected from healthy blood donors without known diseases or intake of medicine.

PICP was determined by an RIA based on antigens from human skin fibroblast cultures with the use of polyclonal rabbit antibodies. ${ }^{3}$ Intra-assay and interassay variations were less than $6 \%$ and $8 \%$, respectively. The detection limit was $1.2 \mu \mathrm{g} / \mathrm{l}$ and the reference interval was $25-225 \mu \mathrm{g} / 1$.

The PIIINP antigenic material was measured by an RIA which is an equilibrium type assay based on a purified propeptide obtained from ascitic fluid..$^{25}$ Intra-assay and interassay variations were less than $5 \%$ and $7 \%$, respectively. The detection limit was 0.2 $\mu \mathrm{g} / 1$ and the reference interval was $1.1-5.3 \mu \mathrm{g} / 1$. All the above mentioned RIA kits are available commercially from Orion Diagnostica, Oulonsalo, Finland.

Intact parathyroid hormone $(\mathrm{PTH})$ was analysed by a two site immunoradiometric assay (Nicholls Institute, San Juan Capistrano, USA). Intra-assay and interassay variations were less than $3 \%$ and $6 \%$, respectively. The detection limit was $1 \mathrm{ng} / \mathrm{l}$ and the reference interval was $10-65 \mathrm{ng} / \mathrm{l}$. Osteocalcin was analysed by a bovine enzyme linked immuosorbent assay (ELISA) technique (Dako, Glostrup, Denmark). Intra-assay and interassay variations were less than $4 \%$ and $8 \%$, respectively. The detection limit was $0.3 \mu \mathrm{g} / \mathrm{l}$ and the reference interval was 3-19 $\mu \mathrm{U} / 1$. 25Hydroxyvitamin D (25-OHD) was determined by RIA as previously described. ${ }^{26}$ Intra-assay and interassay variations were less than $8 \%$ and $10 \%$, respectively. The detection limit was 5 $\mu \mathrm{g} / 1$ and the reference interval was $15-41 \mu \mathrm{g} / \mathrm{l}$. 1,25-Dihydroxyvitamin $\mathrm{D}\left(1,25-\mathrm{OH}_{2} \mathrm{D}\right)$ was 


\begin{tabular}{|c|c|c|}
\hline & $\begin{array}{l}\text { Cirrhotic patients } \\
(n=15)\end{array}$ & Controls $(n=20)$ \\
\hline \multicolumn{3}{|l|}{ Patient characteristics } \\
\hline Height $(\mathrm{cm})$ & $176(159-184) \ddagger$ & $168(155-185)$ \\
\hline Weight (kg) & $74.0(50.0-95.3)$ & $68.5(38.5-105.0)$ \\
\hline Body mass index $\left(\mathrm{kg} / \mathrm{m}^{2}\right)$ & $22.0(17.7-30.8)$ & $24.4(16.0-35.1)$ \\
\hline Age (years) & $59(38-69)$ & $55(30-78)$ \\
\hline Child class $(\mathrm{A} / \mathrm{B} / \mathrm{C})$ & $3 / 6 / 6$ & NA \\
\hline Ascites (Yes/no) & $11 / 4$ & $0 / 20$ \\
\hline Hepatic venous pressure gradient $(\mathrm{mm} \mathrm{Hg} ;<5)^{\star}$ & $18.0(7.0-26.0) \S$ & $3.0(2.0-5.0)$ \\
\hline Hepatic blood flow $(1 / \mathrm{min} ; 0.5-2.3)^{\star}$ & $0.83(0.35-1.61)$ & $1.13(0.90-1.45)$ \\
\hline ICG clearance $(1 / \mathrm{min} ; 0.30-0.70)^{\star}$ & $0.18(0.02-0.45) \S$ & $0.42(0.37-0.61)$ \\
\hline \multicolumn{3}{|l|}{ Blood biochemistry } \\
\hline Serum aspartate aminotransferase $(U / 1 ; 10-40)^{\star}$ & $67(14-430) \ddagger$ & $22(14-52)$ \\
\hline Serum bilirubin $(\mu \mathrm{mol} / 1 ; 2-17)^{\star}$ & $21(5-01) \ddagger$ & $7(5-20)$ \\
\hline Serum alkaline phosphatase $(U / 1 ; 50-275)^{\star}$ & $329(132-1065) \ddagger$ & $194(106-242)$ \\
\hline Plasma coagulation factors 2,7 , and 10 (units; $0.70-1.30)^{\star}$ & $0.71(0.23-0.99) \ddagger$ & $1.18(0.40-1.30) \dagger$ \\
\hline Serum albumin $(\mu \mathrm{mol} / 1 ; 540-800)^{\star}$ & $466(348-671) \S$ & $624(501-698)$ \\
\hline Serum creatinine $(\mu \mathrm{mol} / 1 ; 49-121)^{\star}$ & $79(54-293)$ & $82(54-204)$ \\
\hline Serum sodium $(\mathrm{mmol} / 1 ; 136-146)^{\star}$ & $133(123-142) \S$ & $140(134-144)$ \\
\hline Parathyroid hormone $(\mathrm{ng} / \mathrm{ml} ; 10-65)^{\star}$ & $48(11-111)$ & $58(23-155)$ \\
\hline Serum calcium $(\mathrm{mmol} / 1 ; 2.14-2.57)^{\star}$ & $2.25(2.05-2.42)$ & $2.13(2.00-2.36)$ \\
\hline Serum calcium, albumin adjusted $(\mathrm{mmol} / 1 ; 2.13-2.49)^{\star}$ & $2.37(2.29-2.48) \ddagger$ & $2.27(2.12-2.37)$ \\
\hline Osteocalcin $(\mu \mathrm{g} / 1 ; 3-19)^{\star}$ & $7.6(4.4-33.8) \ddagger$ & $12.8(5-34)$ \\
\hline 25-hydroxyvitamin D $(\mu \mathrm{g} / 1 ; 15-41)^{\star}$ & $8.5(7.0-18.0) \ddagger$ & $16.5(6.0-37.0)$ \\
\hline 1,25-dihydroxyvitamin D (ng/1;17-43) ${ }^{\star}$ & $11.5(6.0-31.0) \ddagger$ & $19.5(8.0-59.0)$ \\
\hline
\end{tabular}

Results are expressed as median (total range).

$\star$ Reference intervals in parentheses.

†One individual in the control group had plasma coagulation factors of 0.40 arbitrary units, due to treatment with

anticoagulants for an iliofemoral artery prosthesis.

$\neq \mathrm{p}<0.05, \mathrm{\$} \mathrm{p}<0.005$ compared with controls.

NA, not applicable.

analysed by RIA as previously described. ${ }^{27}$ Intra-assay and interassay variations were less than $8 \%$ and $13 \%$, respectively. The detection limit was $5 \mathrm{ng} / \mathrm{l}$ and the reference interval was 17-43 ng/l. Reference intervals of markers of bone metabolism were obtained from the Copenhagen Osteoporosis Research Centre.

CDT was determined by RIA as previously described. ${ }^{20}$ Intra-assay and interassay variations were both less than 5\%. The detection limit was $1.0 \mathrm{U} / 1$ and the reference interval was 0-20 U/1 for men and 0-26 U/1 for women.

BONE MINERAL MEASUREMENTS

Bone mineral density (BMD) was measured by dual energy $x$ ray absorptiometry (DEXA) (Norland XR-26 MK II, Norland Scientific Instruments, Fort Atkinson, Wisconsin, USA) in 10 of the patients with cirrhosis. To reduce the spinal lordosis and improve separation of the individual vertebrae, the spinal DEXA measurements of $\mathrm{L} 2-\mathrm{L} 4\left(\mathrm{BMD}_{\mathrm{L} 2 \mathrm{~L} 4}\right)$ were taken using an anterior-posterior view with the patients lying supine on an imaging table with their legs raised by a support for the lower legs. The DEXA measurements of the femoral neck $\left(\mathrm{BMD}_{\mathrm{FN}}\right)$ were performed with the patients lying supine with their legs flat on the table. The DEXA measurements of the distal part of the non-dominant forearm $\left(\mathrm{BMD}_{\mathrm{ARM}}\right)$ were performed along the longitudinal axis of the distal forearm starting $1 \mathrm{~cm}$ proximal to the distal radio-ulnar joint and extending $2.4 \mathrm{~cm}$ in the direction of the elbow. ${ }^{28} \mathrm{BMD}$ in the distal $1.5 \mathrm{~cm}$ of the third metacarpal bone $\left(\mathrm{BMD}_{\mathrm{MCB}}\right)$ was measured as described earlier. ${ }^{29}$ The in vivo precisions of $\mathrm{BMD}_{\mathrm{L} 2 \mathrm{~L} 4}, \mathrm{BMD}_{\mathrm{FN}}, \mathrm{BMD}_{\mathrm{ARM}}$, and $\mathrm{BMD}_{\mathrm{MCB}}$ were less than $1.0 \%, 2.3 \%, 1.8 \%$, and $1.7 \%$, respectively. In order to compare the bone mass measurements of the patients with normal age and sex matched levels, the standard deviation scores ( $Z$ scores) were calculated by the equation: $Z=$ (measured value estimated value $e_{\text {mean for sex and age }}$ /standard deviation $_{\text {sex and age }}{ }^{30} \mathrm{BMD}$ reference intervals have recently been reported from our laboratory. ${ }^{29}$ The reference values of $\mathrm{BMD}_{\mathrm{L} 2 \mathrm{~L} 4}, \mathrm{BMD}_{\mathrm{FN}}$, and $\mathrm{BMD}_{\mathrm{ARM}}$ for women originate from 326 healthy controls, aged 18-79 years, from the Copenhagen area. The reference values of the $\mathrm{BMD}_{\text {L2L4 }}$ for men were provided by Norland Corp. A normal reference range for $\mathrm{BMD}_{\mathrm{MCB}}$ in 108 healthy women, aged 18-79 years, and a normal reference range for $\mathrm{BMD}_{\mathrm{ARM}}$ and $\mathrm{BMD}_{\mathrm{MCB}}$ in 35 healthy men, aged 29-74 years, are reported elsewhere. ${ }^{29}$

\section{STATISTICS}

Results are given as medians and total ranges. The Mann-Whitney test was used to compare variables in patients and controls and the Kruskal-Wallis test was used to test differences between the Child-Turcotte classes. The Wilcoxon test for paired data was used to analyse differences in ICTP in different vessels. Correlations were performed with the Spearman rank correlation test. The two tailed significance level of the type 1 error was fixed at $5 \%$.

\section{Results}

Table 1 summarises clinical, biochemical, and hormonal characteristics of patients and controls.

ICTP

The median circulating concentration of ICTP was significantly higher in the cirrhotic patients $(23.2 \mu \mathrm{g} / \mathrm{l}$, range 3.9-113.0) than in the control subjects $(5.0 \mu \mathrm{g} / \mathrm{l}$, range $3.2-23.6 ; \mathrm{p}<0.0001$, see fig 1A). The ICTP concentrations tended 

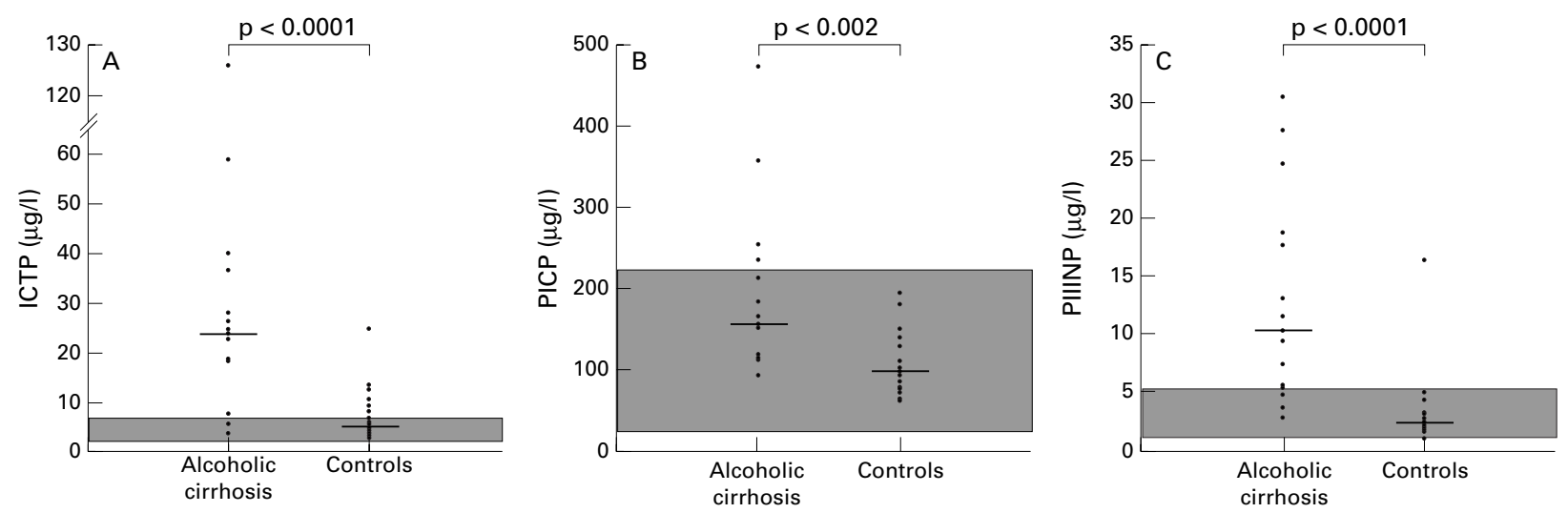

Figure 1 Circulating concentrations of $\operatorname{ICTP}(A), P I C P(B)$, and PIINP $(C)$ in 15 patients with alcoholic cirrhosis and 20 control subjects. Bars represent medians and the grey areas are the normal ranges.

to be lower in Child class A patients $(5.6 \mu \mathrm{g} / \mathrm{l})$ than in class B $(29.9 \mu \mathrm{g} / \mathrm{l})$ and $\mathrm{C}$ patients $(23.0$ $\mu \mathrm{g} / 1)$, but the difference only reached borderline significance $(p=0.07)$. The median ICTP was significantly higher in patients with ascites $(24.4 \mu \mathrm{g} / \mathrm{l})$, than in those without $(12.3 \mu \mathrm{g} / \mathrm{l}$; $\mathrm{p}<0.05)$.

Hepatic and renal venous concentrations and femoral arterial concentrations of ICTP were significantly elevated in the cirrhotic patients, compared with the respective concentrations in the control subjects $(p<0.0001$; table 2). There was no overall significant hepatic extraction of ICTP in either patients or controls. However, the median hepatic venousarterial difference of ICTP was significantly higher in patients with advanced disease and a Child score $>7(1.9 \mu \mathrm{g} / \mathrm{l})$ than in patients with a Child score $\leqslant 7(-0.35 \mu \mathrm{g} / 1 ; \mathrm{p}<0.03)$. In the control subjects a significant renal extraction ratio of ICTP of 0.15 was observed $(p<0.001)$, whereas that in the patient group only reached borderline significance $(0.13, \mathrm{p}=0.09)$, as analysed by a paired test (see fig 2 and table 2 ). In three control subjects with increased serum creatinine, the circulating ICTP concentrations were higher $(12.5 \mu \mathrm{g} / \mathrm{l})$ than in controls with normal serum creatinine $(4.1 \mu \mathrm{g} / \mathrm{l}$; $\mathrm{p}<0.01)$. However, there was no significant difference in renal venous-arterial difference $(-0.6$ versus $-1.6 \mu \mathrm{g} / 1$; NS) or renal extraction $(0.17$ versus $0.10 ; \mathrm{NS})$.

In the patients with cirrhosis, the circulating concentrations of ICTP correlated directly with serum alkaline phosphatases $(r=0.61$, $\mathrm{p}<0.01)$, serum creatinine $(r=0.64, \mathrm{p}<0.01)$, and PIIINP $(r=0.60, \mathrm{p}<0.02)$ and negatively with serum sodium $(r=-0.73, \mathrm{p}<0.001)$. There was no significant correlation between ICTP and PICP $(r=0.38, \mathrm{p}=0.1)$.

PICP

The circulating concentrations of PICP were significantly higher in patients with cirrhosis $(157 \mu \mathrm{g} / \mathrm{l}$, range $93-473)$ than in controls (96 $\mu \mathrm{g} / 1$, range $62-195 ; \mathrm{p}<0.002$, fig $1 \mathrm{~B})$. In the patients with cirrhosis the elevated PICP correlated directly with serum aspartate aminotransferase $(r=0.59, \mathrm{p}<0.02)$ and alkaline phosphatases $(r=0.51, \mathrm{p}<0.05)$ and negatively with serum albumin $(r=-0.64, \mathrm{p}<0.01)$ and the clearance of ICG $(r=-0.60, p<0.02)$. Furthermore, a direct significant correlation was found between PICP and PIIINP $(r=0.68$, $\mathrm{p}<0.005)$. There was no significant relation of PICP to the Child score or to the presence of ascites.

PIIINP

The circulating concentrations of PIIINP were significantly higher in patients with cirrhosis $(10.3 \mu \mathrm{g} / \mathrm{l}$, range $2.8-30.5)$ than in the controls $(2.6 \mu \mathrm{g} / \mathrm{l}$, range $1.0-16.4 ; \mathrm{p}<0.0001$, fig $1 \mathrm{C})$. PIIINP was significantly related to the Child classes with the lowest figures in Child class A $(3.7 \mu \mathrm{g} / \mathrm{l})$, compared with class B $(6.5 \mu \mathrm{g} / \mathrm{l})$ and class $\mathrm{C}(21.8 \mu \mathrm{g} / \mathrm{l} ; \mathrm{p}<0.005)$. In the patients with cirrhosis, PIIINP correlated directly with indicators of liver dysfunction, such as aspartate aminotransferase $(r=0.89, \quad \mathrm{p}<0.001)$, serum bilirubin $(r=0.72, \mathrm{p}<0.005)$, and serum alkaline phosphatases $(r=0.75, \mathrm{p}<0.001)$, and

Table 2 Regional concentrations of carboxy terminal cross linked telopeptide of type I collagen (ICTP) and renal and hepatic venous-arterial differences and extractions in 15 patients with cirrhosis and 20 controls

\begin{tabular}{lll}
\hline ICTP & Cirrhotic patients & Controls \\
\hline Hepatic vein $(\mu \mathrm{g} / \mathrm{l})$ & $23.8(3.6$ to 126.0$) \dagger$ & $5.1(2.7$ to 24.8$)$ \\
Femoral artery $(\mu \mathrm{g} / \mathrm{l})$ & $23.2(3.9$ to 113.0$) \dagger$ & $5.0(3.2$ to 23.6$)$ \\
Hepatic venous-arterial difference $(\mu \mathrm{g} / \mathrm{l})$ & $0.2(-7.5$ to 13.0$)$ & $-0.02(-0.9$ to 1.3$)$ \\
Hepatic extraction ratio & $-0.01(-0.16$ to 0.21$)(\mathrm{NS})$ & $0.00(-0.14$ to 0.21$)(\mathrm{NS})$ \\
Renal vein $(\mu \mathrm{g} / \mathrm{l})$ & $19.8(3.8 \text { to } 119.0)^{\star} \dagger$ & $3.6(2.6$ to 22.5$) \ddagger$ \\
Femoral artery $(\mu \mathrm{g} / \mathrm{l})$ & $22.9(4.3$ to 113.0$) \dagger$ & $4.8(2.7$ to 24.9$)$ \\
Renal venous-arterial difference $(\mu \mathrm{g} / \mathrm{l})$ & $-1.3(-7.9$ to 6.0$)$ & $-0.65(-2.4$ to 2.0$)$ \\
Renal extraction ratio & $0.13(-0.5$ to 23$) \mathbb{S}$ & $0.15(-0.22$ to 0.32$) \mathbb{S}$
\end{tabular}

Results are expressed as median (total range).

${ }^{\star} \mathrm{p}=0.09$ paired Wilcoxon test used for comparisons of venous versus arterial concentrations of ICTP. $t \mathrm{p}<0.0001$ unpaired Mann-Whitney test used for comparisons of patients versus controls.

$\neq \mathrm{p}<0.001$ paired Wilcoxon test used for comparisons of venous versus arterial concentrations of ICTP.

$\S$ Significantly different from zero, $\mathrm{p}<0.01$. 

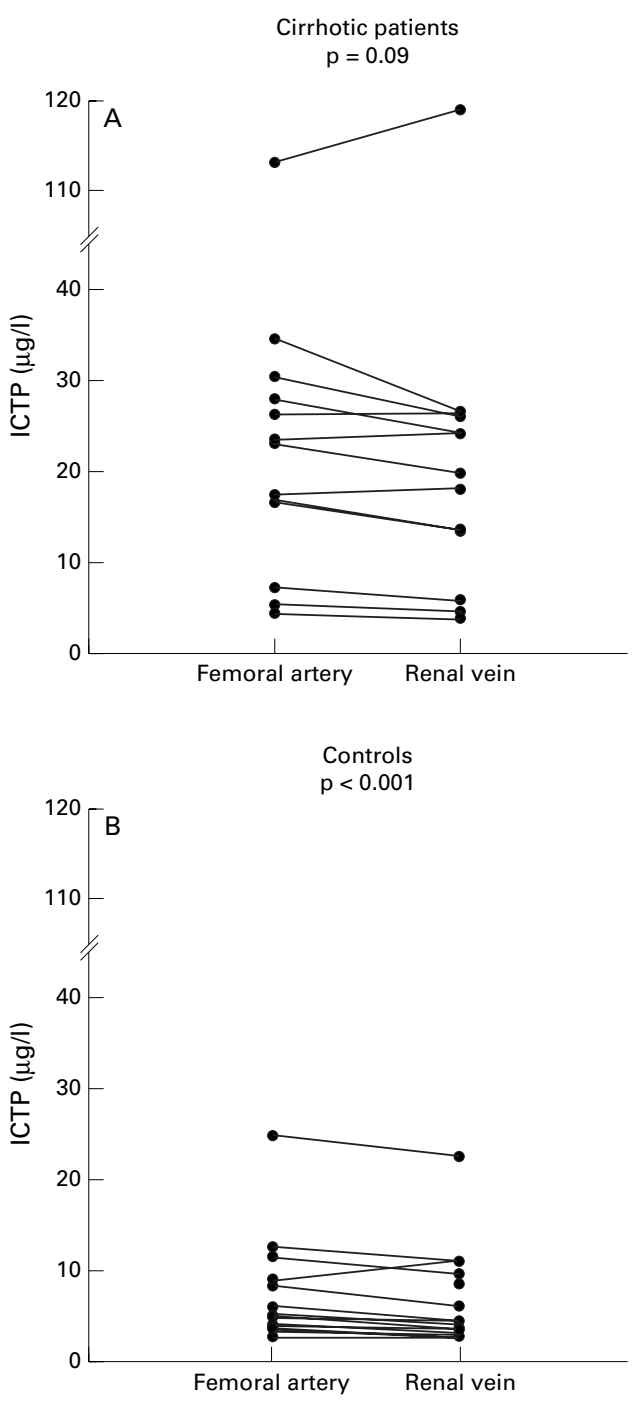

Figure 2 Concentrations of ICTP in the femoral artery and renal vein in patients with cirrhosis $(A ; n=13)$ and subjects with normal liver function $(B ; n=19)$. In subjects with normal liver function there was a significant renal extraction of ICTP of $0.15(p<0.001)$, whereas the renal extraction of 0.13 in the cirrhotic patients was only of borderline significance $(p=0.09)$.

negatively with serum sodium $(r=-0.58$, $\mathrm{p}<0.02)$, coagulation factors 2,7 , and 10 $(r=-0.51, \mathrm{p}<0.05)$, serum albumin $(r=-0.74$, $\mathrm{p}<0.001)$, and clearance of ICG $(r=-0.86$, $\mathrm{p}<0.001)$. No relation between PIIINP and the presence or absence of ascites was observed.

\section{DUAL ENERGY $X$ RAY ABSORPTIOMETRY}

$\mathrm{BMD}_{\mathrm{L} 2 \mathrm{~L} 4}$ and $\mathrm{BMD}_{\mathrm{FN}}$ were within the normal range in all patients with cirrhosis with a median $\mathrm{Z}$ score of 0.64 (range -1.57 to 1.90 , NS) and -0.63 (range -1.72 to $1.16, \mathrm{NS}$ ), respectively. $\mathrm{BMD}_{\mathrm{ARM}}$ was significantly decreased in the male patients with alcoholic cirrhosis $\left(0.45 \mathrm{~g} / \mathrm{cm}^{2}\right.$, range $0.37-0.53$ versus 0.53 $\mathrm{g} / \mathrm{cm}^{2}$, range $\left.0.40-0.64 ; \mathrm{p}<0.05\right)$, and $\mathrm{BMD}_{\mathrm{MCB}}$ was decreased in the female patients ( $\mathrm{Z}$ score -1.52 to $-0.74, p<0.01)$. We found no significant correlations between DEXA measurements and ICTP, PICP, PIIINP or with markers of liver impairment.
BONE METABOLISM

Intact PTH was slightly lower in patients with cirrhosis than in controls although this difference did not reach statistical significance. Total serum calcium was not significantly different between the groups. When adjusted to serum albumin, the calcium concentrations were higher in patients with cirrhosis $(p<0.01$, see table 1), but all figures were within the normal range.

Serum osteocalcin was significantly lower in patients with cirrhosis than in control subjects $(\mathrm{p}<0.05)$ and correlated directly with PTH $(r=0.67, \mathrm{p}<0.03)$ and coagulation factors 2,7 , and $10(r=0.74, \mathrm{p}<0.005)$ and negatively with serum bilirubin $(r=-0.68, \mathrm{p}<0.05)$. No significant correlations between osteocalcin and ICTP, PICP, or PIIINP were observed.

25-OHD and $1,25(\mathrm{OH})_{2} \mathrm{D}$ were significantly reduced in patients with cirrhosis compared with controls $(p<0.02)$. In patients with cirrhosis no significant correlations between vitamin $\mathrm{D}$ metabolites and indicators of liver and renal function or fibrosis were found.

The CDT level was significantly higher in patients with cirrhosis than in controls $(\mathrm{p}<0.05)$ but only five patients had CDT figures above the upper normal range.

\section{Discussion}

It has been claimed that ICTP is a specific marker of bone collagen degradation and therefore reflects the degree of bone resorption and the severity of metabolic bone disease. ${ }^{9}$ A significant relation between ICTP and the degree of bone resorption, as assessed by histomorphometry, has been described in patients with different types of metabolic bone diseases. ${ }^{47}$ ICTP is primarily released from the bones, but other organs (the skin and tendons), may contribute to the circulating concentrations. ${ }^{31}$ The sites of degradation of ICTP are at present unknown. ICTP is a small molecule with a molecular weight of 9-12 kDa and may therefore be eliminated by the kidneys. ${ }^{92}$ Risteli et al found an increased serum level of ICTP in patients with renal disorders and reduced glomerular filtration. ${ }^{9}$ Our findings of increased circulating and hepatic venous concentrations of ICTP in patients with cirrhosis are consistent with recent results of Ricard-Blum et al who described elevated ICTP concentrations in patients with liver diseases of various aetiologies. ${ }^{33}$ Recent results of increased ICTP in patients with granulomatous hepatic fibrosis support the view that in chronic liver disease, ICTP more likely reflects remodelling of hepatic fibrosis and the authors conclude that ICTP could thus be a potential marker of active fibrosis in the liver. ${ }^{34}$ Although the overall ICTP concentrations were lower in the control group than in the cirrhotic patients, five control subjects had ICTP concentrations above the upper normal limit of $6.2 \mu \mathrm{g} / 1$. These individuals had more advanced arterial hypertension or arteriosclerosis and probably a higher degree of fibrogenic activity, which may account for the increase in ICTP. Three control subjects had increased creatinine and ICTP concentrations but the renal extraction 
was not significantly different from those with normal serum creatinine. However, it cannot be excluded that renal impairment in these patients may contribute to the increased circulating ICTP concentrations.

In our study we found no overall hepatic extraction in either patients with cirrhosis or in the controls. Although the hepatic venousarterial difference in ICTP was slightly increased in the patients with advanced cirrhosis, our results indicate only a small hepatic production or a very low turnover rate of ICTP in the circulation. In contrast, significant renal extraction was found in the controls whereas it was only of borderline significance in the cirrhotic patients. This finding lends support to the assumption that ICTP in normal subjects may be degraded in the kidneys. An additional explanation for the increased concentrations of ICTP in chronic liver disease could be impaired renal function, as previously indicated. ${ }^{9}$ This assumption is supported by the significant correlations between ICTP and indicators of renal dysfunction, such as serum sodium and creatinine in the cirrhotic patients and the fact that five of the patients had serum creatinine above the normal range. However, the renal extraction of ICTP in those five patients was not significantly different from the 10 with normal levels of serum creatinine. Furthermore, renal blood flow is decreased in patients with cirrhosis ${ }^{35}$ which may further affect the renal elimination of ICTP. Nevertheless, we have found significant correlations between ICTP and indicators of liver function, as well as to indicators of renal dysfunction but not between ICTP and bone mineral content or markers of bone metabolism. Thus, the elevated circulating concentrations of ICTP in cirrhosis most likely reflect the combination of liver fibrosis and hepatic nephropathy often seen in these patients. ${ }^{33} 3637$

Many studies concern bone metabolism in patients with chronic liver disease and the presence of both osteoporosis and osteomalacia has been described. ${ }^{11}{ }^{13}$ Patients with alcoholic liver disease have been reported to suffer an increased risk of osteopenia, as alcohol may suppress bone formation and mineralisation. ${ }^{14}$ However, the effects of alcohol on bone metabolism are complicated, as recent studies have suggested that a moderate intake of alcohol may even be beneficial to bone structure. ${ }^{14}$ The slightly increased CDT levels in our patients with cirrhosis indicate a current intake of alcohol, and therefore a toxic effect on bone metabolism cannot be excluded. Low levels of PTH, osteocalcin, 25-OHD, and $1,25(\mathrm{OH})_{2} \mathrm{D}$ have previously been described in cirrhosis. ${ }^{11} 1315$ In our patients these abnormalities may reflect the presence of hepatic osteodystrophy and/or various degrees of intestinal vitamin $\mathrm{D}$ malabsorption, abnormal hepatic metabolism of vitamin $\mathrm{D}$, or toxic effects of alcohol on bone metabolism as mentioned above. ${ }^{1838}$ However, our findings of a nearly normal axial bone mineral density and serum calcium indicate only a mild degree of osteodystrophy without any association of bone metabolism and ICTP. This combination of a nearly normal bone mineral density and elevated ICTP support ICTP as primarily a marker of non-bone connective tissue metabolism-that is, hepatic fibrosis in our patients. However, in other patients with advanced liver disease and osteodystrophy, as for example in primary biliary cirrhosis, a relation between ICTP and osteopenia cannot be excluded. Recent results in patients with cirrhosis have shown decreased bone mineral density in those with advanced disease and without correlations to the clinical severity of the cirrhosis. ${ }^{16}{ }^{17}$ However, our findings in a smaller, consecutive study population support the assumption that osteoporosis may not occur frequently in early alcoholic cirrhosis; in these patients, the aetiology may be multifarious - that is, malnutrition and decreased physical activity. The latter accords with the decreased appendicular bone mass we observed in our cirrhotic patients.

PICP has been put forward as a specific marker of osteoblast function ${ }^{3}$ and various reports have emerged on relations between PICP and histomorphometry and other markers of bone formation, such as alkaline phosphatases and osteocalcin. ${ }^{67}$ In our study, the increased PICP in cirrhotic patients correlated with indicators of liver failure, such as aminotransferases, albumin, alkaline phosphatases, and ICG clearance, but not with DEXA measurements or ICTP. In contrast, PICP correlated to PIIINP, a marker of hepatic fibrosis in cirrhosis. ${ }^{39}{ }^{40}$ It is therefore conceivable that the circulating level of PICP in patients with chronic liver disease merely reflects the liver dysfunction more than bone metabolism. This problem should be further elucidated in studies involving assessment with bone histomorphometry.

In conclusion, ICTP was elevated in cirrhosis with signs of hepatic production of ICTP in patients with advanced disease. In patients with cirrhosis ICTP was related to liver function. In the controls there was no major hepatic production or disposal, whereas significant renal extraction was found. The cirrhotic patients had only mild osteodystrophy without relation to ICTP. As our patients conceivably had only a mild degree of osteopenia, elevated ICTP may primarily reflect hepatic fibrosis and should not be used for the assessment of hepatic osteodystrophy.

This study is dedicated to Kirsten D Bentsen, MD (28.05.4813.05.96) who has inspired and encouraged the present work. The study was hork. The study was supported by grants from the John and Birthe Meyer Foundation, the Danish Medical Research Council, and express their gratitude to Hanne Hansen MSc, for her excellent assistance in handling the database.

1 Mundy GR. Bone remodelling and its disorders. London: Martin Dunitz, 1995.

2 Delmas PD. Biochemical markers of bone turnover. 7 Bone Miner Res 1993;8(suppl 12):549-55.

3 Melkko J, Niemi S, Risteli L, et al. Radioimmunoassay of the carboxyterminal propeptide of human type I procollagen. Clin Chem 1990;36:1328-32.

4 Parfitt AM, Simon LS, Villanueva AR, et al. Procollagen type I carboxy-terminal extension peptide in serum as marker of collagen biosynthesis in bone. Correlation with iliac bone formation rates and comparison with total alkaline phosphatase. F Bone Miner Res 1987;2:427-36.

5 Hassager C, Jensen LT, Johansen JS, et al. The carboxyHassager C, Jensen LT, Johansen JS, et al. The carboxy-
terminal propeptide of type I procollagen in serum as a 
marker of bone formation: the effect of nadrolone decanoate and female sex hormones. Metabolism 1991;40: 205-8.

6 Ebeling PR, Peterson JM, Riggs BL. Utility of type I procollagen propeptide assays for assessing abnormalities in metabolic bone diseases. F Bone Miner Res 1992;7:124350.

7 Eriksen EF, Charles P, Melsen F, et al. Serum markers of type I collagen formation and degradation in metabolic bone disease: correlation with bone histomorphometry. $\mathcal{F}$ Bone Miner Res 1993;8:127-32.

8 Elomaa I, Virkkunen P, Risteli L, et al. Serum concentration of the cross-linked carboxyterminal telopeptide of type I collagen (ICTP) is a useful prognostic indicator in multiple myeloma. Br F Cancer 1992;66:337-41.

9 Risteli J, Elomaa I, Niemi S, et al. Radioimmunoassay for the pyridinolin cross-linked carboxyterminal telopeptide of type I collagen: a new serum marker of bone collagen degtype I collagen: a new serum marker of
radation. Clin Chem 1993;39:635-40.

10 Compston JE. Hepatic osteodystrophy: vitamin D metabolism in patients with liver disease. Gut 1986;27:1073-90.

11 Diamond TH, Stiel DS, Lunzer M, et al. Hepatic osteodystrophy. Static and dynamic bone histomorphometry and serum bone gla-protein in 80 patients with chronic liver disease. Gastroenterology 1989;96:213-21.

12 Diamond TH, Stiel DS, Lunzer M, et al. Ethanol reduces bone formation and may cause osteoporosis. $\mathrm{Am} \mathcal{F} \mathrm{Med}$ 1989;86:282-8

13 Diamond TH, Stiel DS, Lunzer M, et al. Osteoporosis and skeletal fractures in chronic liver disease. Gut 1990;31:82-7. 14 Rico H. Alcohol and bone disease. Alcohol Alcohol 1990;25: 345-52.

15 Monegal A, Navasa M, Guanabens N, et al. Osteoporosis and bone mineral metabolism disorders in cirrhotic patients referred for orthotopic liver transplantation. Calcif Tissue Int 1997;60:148-54.

16 Kalefezra JA, Merkouropoulos MH, Challa A, et al. Amount and composition of bone minerals in chronic liver disease. and composition of bone mineral

17 Chen CC, Wang SS, Jeng FS, et al. Metabolic bone disease of liver cirrhosis: is it parallel to the clinical severity of cirof liver cirrhosis: is it parallel to the clinical severit
rhosis? $\mathcal{F}$ Gastroenterol Hepatol 1996;11:417-21.

18 Idilman R, Demaria N, Uzunalimoglu O, et al. Hepatic osteodystrophy: a review. Hepatogastroenterology 1997;44 $574-81$

19 Fabris C, Falleti E, Federico E, et al. A comparison of four serum markers of fibrosis in the diagnosis of cirrhosis. Ann Clin Biochem 1997;34:151-5.

20 Henriksen JH, Grønbæk M, Møller S, et al. Carbohydrate deficient transferin (CDT) in alcoholic cirrhosis: a kinetic study. ₹ Hepatol 1997;26:287-92.

21 Rubio M, Caballeria J, Deulofeu R, et al. Carbohydratedeficient transferrin as a marker of alcohol consumption in male patients with liver disease. Alcohol Clin Exp Res 1997; 21:923-7.

22 Gluud C, The Copenhagen Study Group for Liver Diseases. Serum testosterone concentration in men with alcoholic cirrhosis: background for variation. Metabolism 1987;36: cirrhosis:

23 Henriksen JH, Ring-Larsen H, Kanstrup I-L, et al. Splanchnic and renal elimination and release of catecholamines in cirrhosis. Evidence of enhanced sympathetic nervous activity in patients with cirrhosis. Gut 1984;25:1034-43.

24 Henriksen JH, Winkler W. Hepatic blood flow determination. A comparison of 99-Tc-diethyl-IDA and indocyanine green as hepatic blood flow indicators in man. 7 Hepatol 1987;4:66-70

25 Risteli J, Niemi S, Trivedi P, et al. Rapid equilibrium radiommunoassay for the amino-terminal propeptide of human III-procollagen. Clin Chem 1988;34:715-18.

26 Lund B, Sørensen OH. Measurement of 25-hydroxyvitamin $\mathrm{D}$ in serum and its relation to sunshine, age and vitamin D intake in the Danish population. Scand $\mathcal{F}$ Clin Lab Invest 1979;39:23-30.

27 Lund B, Sørensen OH. Measurement of circulating 1,25 -dihydroxyvitamin $\mathrm{D}$ in man. Changes in serum
concentrations during treatment with 1 -alfaconcentrations during treatment with
hydroxycholecalciferol. Acta Endocrinol 1979;91:338.

28 Kollerup G, Sørensen HA. Bone mass in the forearm by dual photon energy X-ray absorptiometry. In: Christiansen C, Overgaard K, eds. Osteoporosis. Copenhagen: Osteopress, 1990:736-8.

29 Hansen M, Florescu A, Stoltenberg M, et al. Bone loss in rheumatoid arthritis. Influence of disease activity, duration of the disease, functional capacity and corticosteroid treatment. Scand F Rheumatol 1996;25:367-76.

30 Armitage P, Berry G. Statistical methods in medical research. Oxford: Blackwell Science, 1990.

31 Risteli L. Assay of collagen metabolism. Helsinki: Orion Diagnostica, 1993.

32 Hassager C, Jensen LT, Pødenphant J, et al. The carboxy-terminal pyridinoline cross-linked telopeptide of type I collagen in serum as a marker of bone resorption. The effect of nandrolone decanoate and hormone replacement therapy. Calcif Tissue Int 1994;54:30-3.

33 Ricard-Blum S, Chossegros P, Guerret S, et al. The carboxy-terminal cross-linked telopeptide of type I collagen (ICTP) is a potential serum marker of ongoing liver fibrosis. Clin Chim Acta 1996;248:187-95.

34 Ricard-Blum S, Bresson-Hadni S, Guerret S, et al. Mechanism of collagen network stabilization in human irreversible granulomatous liver fibrosis. Gastroenterology 1996;111:172-82.

35 Ring-Larsen H, Hesse B, Henriksen JH, et al. Sympathetic nervous activity and renal and systemic hemodynamics in cirrhosis. Plasma norepinephrine concentration, hepatic extraction, and renal release. Hepatology 1982;2:304-10.

36 Epstein M. Hepatorenal syndrome-emerging perspectives of pathophysiology and therapy. F Amer Soc Nephrol 1994; 4:1735-53.

37 Henriksen JH, Ring-Larsen H. Hepatorenal disorders: role of the sympathetic nervous system. Semin Liver Dis 1994;14:35-43.

38 Sampson HW. Alcohol, osteoporosis, and bone regulating hormones. Alcohol Clin Exp Res 1997;21:400-3.

39 Trinchet J-C, Hartmann DJ, Paterson D, et al. Serum type I collagen and N-terminal peptide of type III procollagen in chronic hepatitis. F Hepatol 1991;12:139-44.

40 Bentsen KD. Type III procollagen peptide: studies on the circulating peptides as a marker of fibrogenesis with special reference to the liver. København: Lægeforeningens Forlag, 1992. 